\title{
ИССЛЕДОВАНИЕ ВОЗМОЖНОСТИ ИСПОЛЬЗОВАНИЯ ПРОГРАММНОГО ПРОДУКТА «ПАНОРАМА - РЕДАКТОР П ПРИ СОЗДАНИИ И ОБНОВЛЕНИИ ЦИФРОВЫХ ТОПОГРАФИЧЕСКИХ КАРТ И ПЛАНОВ НА ТЕРРИТОРИЮ РЕСПУБЛИКИ КАЗАХСТАН
}

\section{Марина Сергеевна Еиифанова}

Сибирский государственный университет геосистем и технологий, 630108, Россия, г. Новосибирск, ул. Плахотного, 10, обучающийся, тел. (702)349-21-28, e-mail: m.skorob@mail.ru

\section{Елена Павловна Хлебникова}

Сибирский государственный университет геосистем и технологий, 630108, Россия, г. Новосибирск, ул. Плахотного, 10, кандидат технических наук, доцент кафедры фотограмметрии и дистанционного зондирования, тел. (383)361-08-66, e-mail: e.p.hlebnikova@sgugit.ru

Рассмотрены функциональные особенности векторизатора «Панорама-редактор» с целью создания цифрового топографического плана масштаба 1:2 000, проанализированы возможности его использования на производстве в Республике Казахстан.

Ключевые слова: геинформационные системы, цифровые топографические планы, классификатор условных знаков, MicroStation, профессиональный векторизатор «Панорамаредактор»

\section{STUDY OF THE POSSIBILITY OF USING THE SOFTWARE "PANORAMA-EDITOR" WHEN CREATING AND UPDATING DIGITAL TOPOGRAPHIC MAPS AND PLANS OF THE REPUBLIC OF KAZAKHSTAN}

\section{Marina S. Yepifanova}

Siberian State University of Geosystems and Technologies, 10, Plakhotnogo St., Novosibirsk, 630108, Russia, Student, phone: (702)349-21-28, e-mail: m.skorob@mail.ru

\section{Elena P. Khlebnikova}

Siberian State University of Geosystems and Technologies, 10, Plakhotnogo St., Novosibirsk, 630108, Russia, Ph. D., Associate Professor, Department of Photogrammetry and Remote Sensing, phone: (383)361-08-66, e-mail: e.p.hlebnikova@sgugit.ru

The functional features of the vectorizer "Panorama-editor" for the purpose of creating a digital topographic plan of 1:2000 scale are considered, the possibilities of use in production in the Republic of Kazakhstan are analyzed.

Keywords: geoinformation systems, digital topographic plans, classifier of conventional signs, MicroStation, professional vectorizer "Panorama-editor"

\section{Введение}

Благодаря огромному выбору программного и аппаратного обеспечения, использование всех возможностей компьютерных технологий позволяет хранить большой объем информации. В связи с этим появилась необходимость перевода 
картографической продукции в цифровой формат. На смену бумажным топографическим картам и планам пришли цифровые.

Цифровой топографический план включает в себя не только графическую модель, но и обладает свойством упрощенного использования геодезической информации.

Все виды картографической продукции в виде электронных и цифровых карт и планов нашли широкое применение в промышленности, сельском хозяйстве, использовании природных ресурсов, поиске полезных ископаемых, мониторинге экологической обстановки. Цифровые топографические карты и планы позволяют получать достаточные знания о земной поверхности, местности, плотности населения, густоте дорожной или речной сети и т.д. [1].

Цифровые топографические карты и планы должны содержать максимально точное описание расположения реальных объектов местности в принятой государственной системе координат и их семантических характеристик (свойств). Свойства объектов описываются с применением единых классификаторов (справочников), обеспечивающих автоматизированный обмен и обработку данных цифровых топографических карт и планов. Элементы оформления бумажных топографических карт и планов (зарамочное оформление, линии сетки координат, подписи характеристик, линии рельефа, заполняющие условные знаки и т.д.) не входят в состав цифровых продуктов, они создаются автоматизировано при подготовке цифровых карт и планов к изданию.

Целью выполняемой работы являлось создание цифрового топографического плана посредством двух программных продуктов: MicroStation и «Панорама-редактор», выявить достоинства и недостатки программ, а также провести анализ возможности использования альтернативного программного комплекса для создания и обновления топографических планов на территорию Республики Казахстан.

\section{Методы и материаль}

На сегодняшний день существует три вида графических систем: CAD, Mapping, полнофункциональные геоинформационные системы. CAD - это системы для автоматизированного проектирования с использованием средств машинной графики. Эти системы работают с использованием технических чертежей, поэтому вычерчивание составляет около 70 \% работы. Mapping (картографирование) - программные продукты, предназначенные для профессионального производства цифровых, электронных карт и планов. Геоинформационные системы - системы, включающие в себя средства анализа данных, на основе которых выполняется построение новых карт и планов и создание базы данных [2].

Программа MicroStation (BentleySystems, Inc., США) - это графическая система для автоматизированного конструирования и проектирования в машиностроении, приборостроении, архитектуре, строительстве, геодезии и картографии.

MicroStation выполняет работы с файлами проекта в формате design file. Для работы с растровыми изображениями в программе MicroStation предусмотрено 
приложение для очистки растрового изображения, его трансформирования и масштабирования. Благодаря этому работа со слоями удобна и проста [3].

Проект «Панорама» - это набор геоинформационных технологий, включающий в себя профессиональную ГИС «Карта 2005», промышленный векторизатор электронных карт «Панорама-Редактор». Проект «Панорама» разработан в ЗАО «КБ Панорама» (г. Москва, Россия).

Векторизатор «Панорама-редактор» предназначен для создания электронных карт любого масштаба и обновления уже существующих электронных карт. Программа позволяет создавать и обновлять электронные карты местности, трансформировать растровые и векторные данные, выполнять сшивку и нарезку листов электронной карты, вести библиотеки условных знаков, осуществлять контроль качества данных, импортировать информацию из других форматов, экспортировать информацию в другие системы [4].

В качестве основы использовалось растровое изображение, полученное в результате цифровой аэросъемки.

Основные характеристики указываются в паспорте цифровой аэрофотосъемки, которые представлены в таблице.

Паспорт цифровой аэрофотосъемки

\begin{tabular}{|l|l|}
\hline Территория аэросъемки в границах & Город Шымкент \\
\hline Площадь аэросъемки & 1111 кв. км \\
\hline Масштаб аэросъемки & $1: 27700$ \\
\hline Высота фотографирования & 1736 м \\
\hline Тип камеры & ADS-40 \\
\hline Размер пикселя в мкм & 6,5 микрона \\
\hline Разрешение на местности & 0,18 м \\
\hline Фокусное расстояние & 62,77 м \\
\hline Поперечное перекрытие маршрутов & $30 \%$ \\
\hline Продольное перекрытие маршрутов & $100 \%$ \\
\hline Направление маршрутов & Север-юг \\
\hline Количество маршрутов & 48 \\
\hline Количество аэроснимков & 2304 \\
\hline
\end{tabular}

После полевых и летно-съемочных работ проводится первичная обработка данных цифровой аэросъемки для преобразования изображения в растровый файл. В дальнейшем с помощью фотограмметрической обработки с использованием программного обеспечения GPro, получают изображение, исключающее геометрические искажения. Создание мозаики выполняется в программном продукте ERDAS Inc. (Leica Photogrammetry Suite), отдельные ортофотоизображения сшиваются в общую мозаику посередине зон перекрытий маршрутов. В процессе 
формирования цифрового ортофотоплана выполняется выравнивание изображений по фототону, включая единую яркость, контраст, цветовой тон. Выполняется цифровая коррекция. Результатом фотограмметрической обработки данных аэросъемки являются ортофотопланы и цифровая модель рельефа [5].

\section{Результаты}

На первом этапе работы с помощью программы MicroStation создан цифровой топографический план масштаба 1:2 000 (Республика Казахстан, Туркестанская область, город Шымкент) [6].

Следующим этапом работы стало создание цифрового топографического плана масштаба 1:2 000 в профессиональном векторизаторе «Панорама - Редактор». В качестве исходного материала был использован тот же ортофотоплан, фрагмент которого показан на рис. 1.

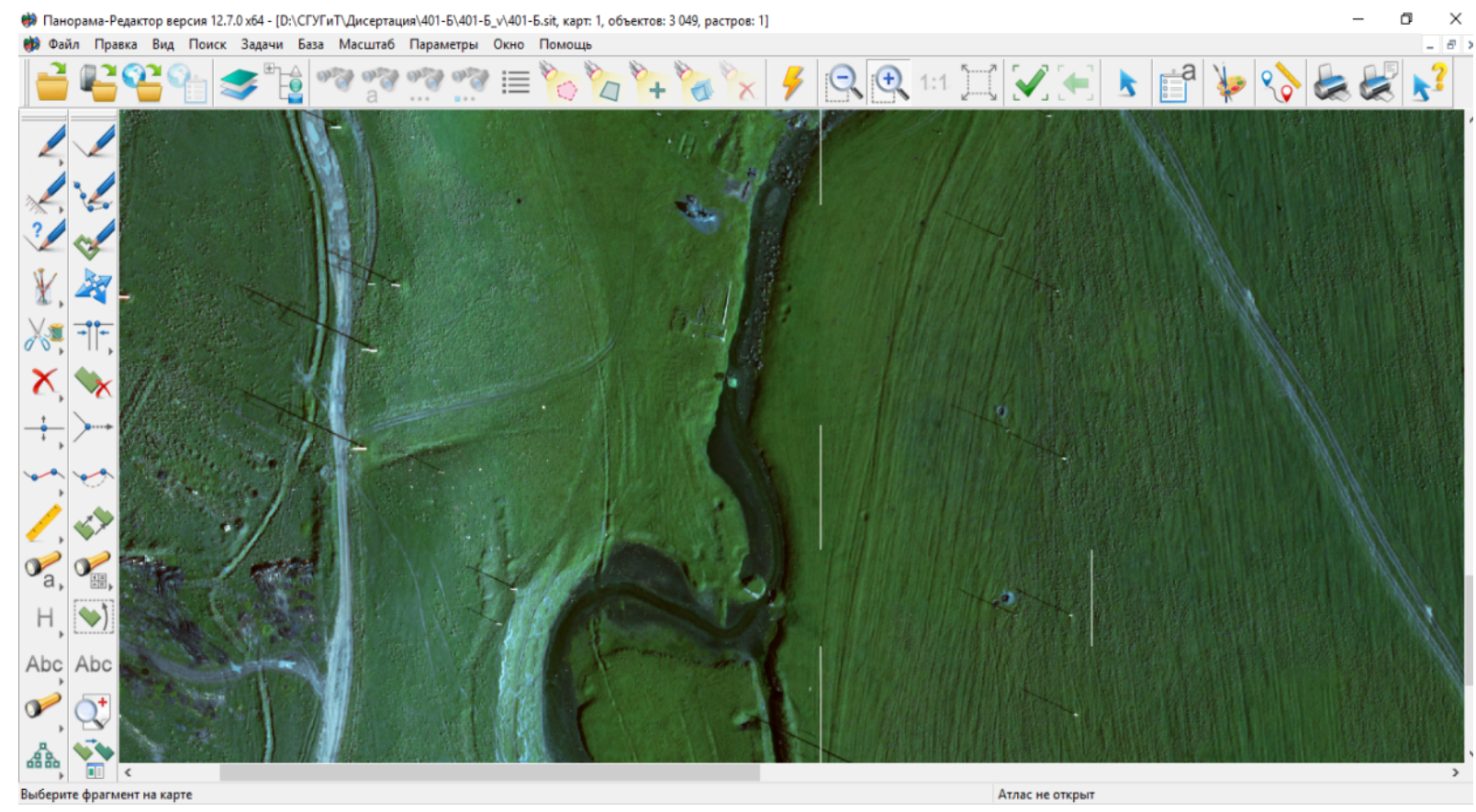

Рис. 1. Фрагмент окна программного комплекса «Панорама-редактор»

Одним из критериев выбора данного программного продукта стало наличие встроенного цифрового классификатора.

Цифровой классификатор - это совокупность описания слоев векторной карты, видов объектов и их условных знаков, видов семантических характеристик и принимаемых ими значений, представленных в цифровом виде. Классификатор карты в цифровом виде хранится в файле RSC. В этом случае несколько карт из разных директорий могут применять один классификатор. Любое изменение в классификаторе отображается на всех картах. Редактор классификатора может быть вызван из списка прикладных задач, а также через всплывающее меню в легенде карты или диалоге выбора объекта. Окно цифрового классификатора показано на рис. 2. 


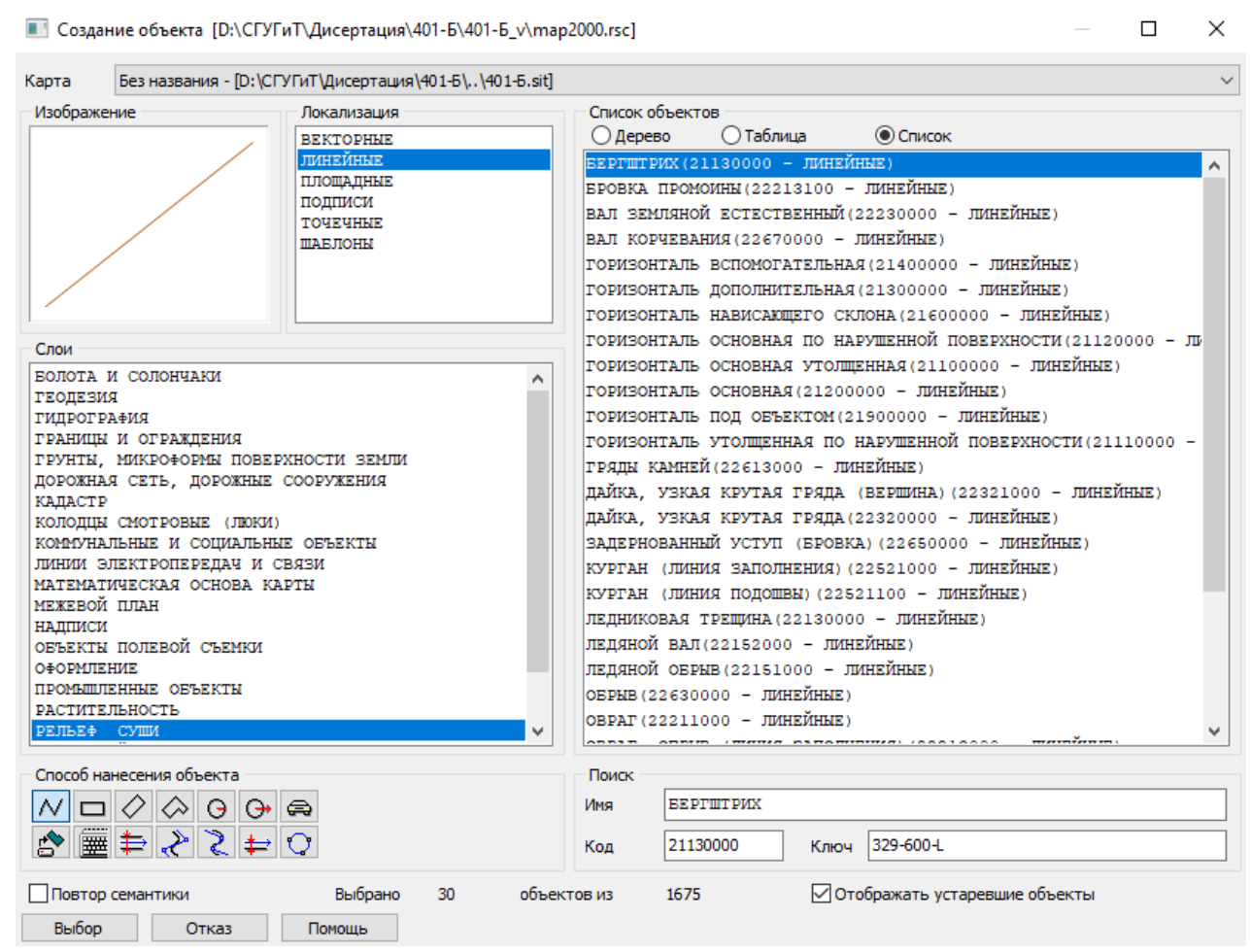

Рис. 2. Фрагмент окна цифрового классификатора

Перед началом векторизации необходимо выполнить работу по оптимизации и редактированию цифрового классификатора [7].

$\mathrm{B}$ процессе создания цифрового классификатора определяют вид, масштаб и назначение электронной карты, для которой создается классификатор, перечень создаваемых условных знаков, их вид, состав характеристик, деление на слои, способ кодирования и так далее. В качестве основы для определении состава объектов, вида соответствующих им условных знаков и способа кодирования объектов и их характеристик служат стандартные классификаторы для карт и планов масштабов 1:500 - 1:10 000 и для карт масштабов 1:25 000, 1:1 000000. В результате должны быть собраны сведения о палитре карты, шрифтах, слоях карты, объектах и семантике.

Основной задачей палитры классификатора является отображение объектов на экране. Она может включать в себя 16, 32, 64, 256 цветов. Зачастую для создания карты или плана достаточно палитры из 32 цветов в формате RGB. Для офсетной печати необходима дополнительная палитра в формате СMYК равная числу цветов палитры RGB [8]. Для изображения подписей используются шрифты TrueType, установленные в операционной системе Windows стандартным образом. В разделе «Редактирование шрифтов» можно поменять цвет, высоту (в миллиметрах) и другие свойства шрифта.

Семантические характеристики служат для описания атрибутов объектов. Каждая характеристика состоит из названия, ключа (до 16 символов), кода характеристики (от 1 до 65 535), типа значения, единицы измерения (7 символов), минимального и максимального значения характеристик. 
Создание, редактирование и обновление цифровой модели местности выполняется при помощи Редактора векторной карты.

Для вызова инструментальной панели необходимо в меню «Задачи» выбрать пункт «Редактор карты» как показано на рис. 3.

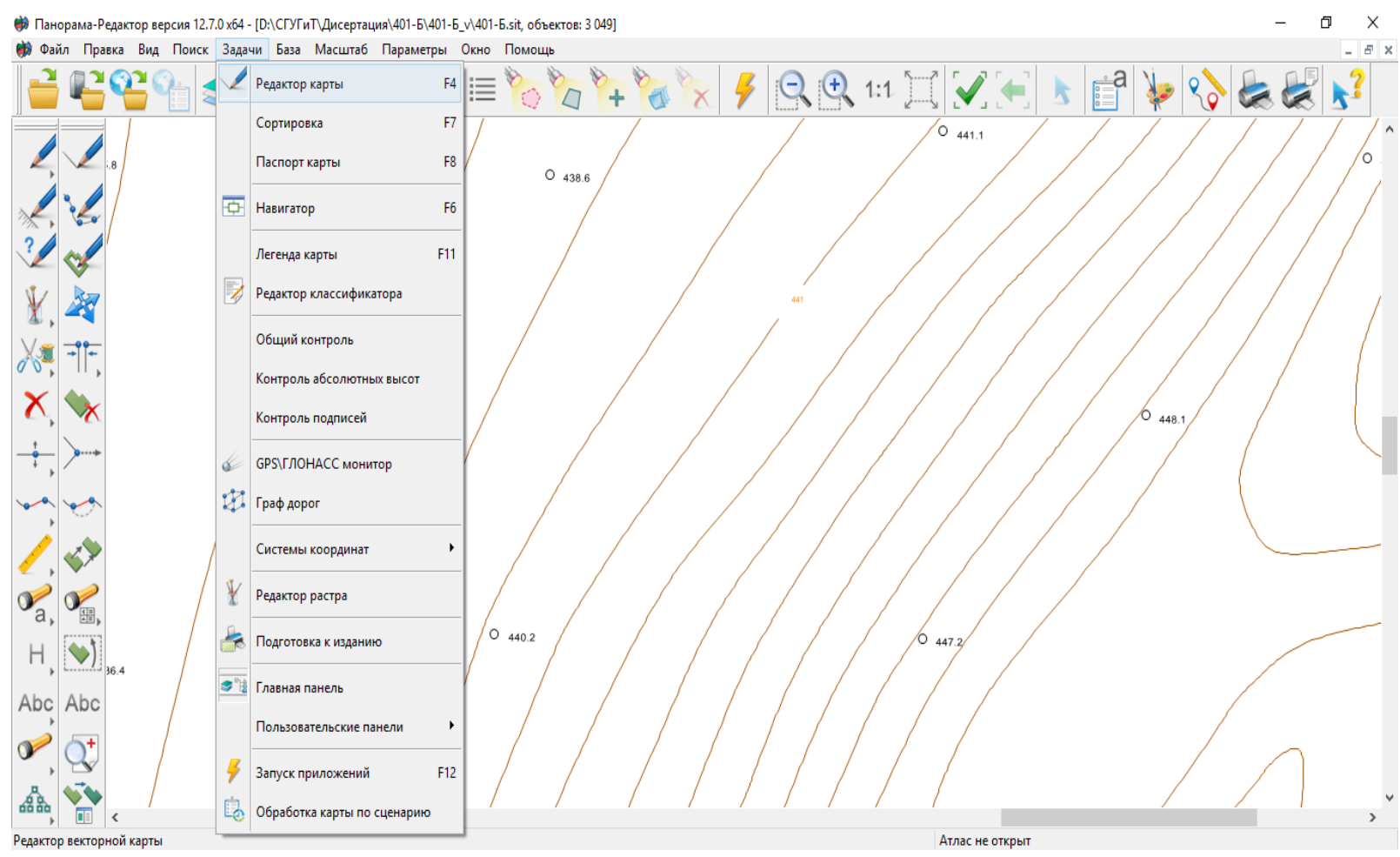

Рис. 3. Редактор карты

С помощью Редактора векторной карты можно создать новый объект, используя электронный классификатор. Также, используя данную панель, можно создать копию существующего на карте объекта, перенести объект, создать вокруг объекта зону необходимой ширины, создать зеркальную копию объекта, создать группу объектов, подписать объект текстом и многое другое.

Создание и обновление элементов планово-высотной основы выполняется в процессе фотограмметрической обработки аэрофотосъемки. Для того чтобы перенести на создаваемую карту объекты планово-высотной основы следует выделить на пользовательской карте все объекты и выполнить перенос выделенных объектов [9].

\section{Заключение}

Результатом данного исследования стало создание цифрового топографического плана масштаба 1:2 000 на территории Республики Казахстан, город Шымкент в программе MicroStation и векторизаторе «Панорама-редактор», фрагменты которых показаны на рис. 4. 


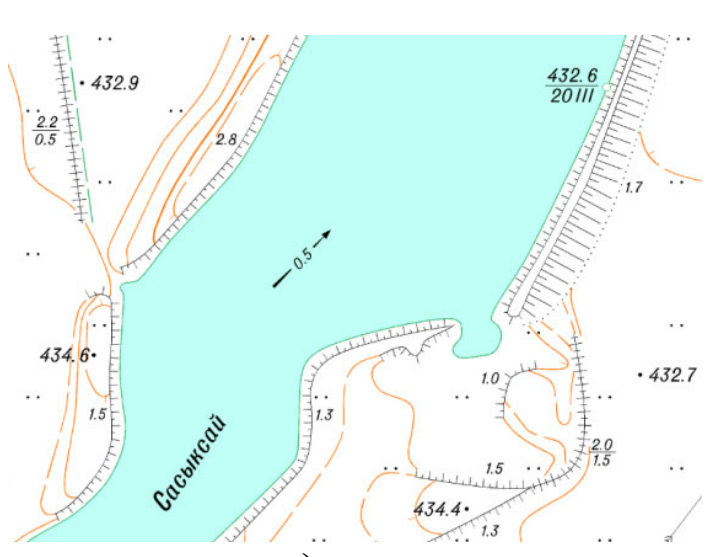

a)

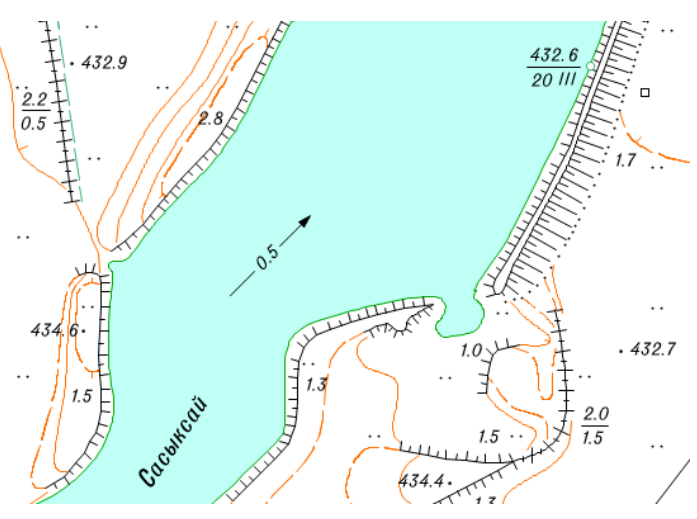

б)

Рис. 4. Фрагмент цифрового топографического плана масштаба 1:2 000:

a) программа «MicroStation»; б) профессиональный векторизатор «Панорама-редактор»

В качестве исходных материалов использовался ортофотоплан, материалы полевого и камерального дешифрирования и карты открытого пользования. В ходе работы установлено, что обе программы подходят для создания цифрового топоргафического плана. Удобная система настройки интерфейса позволяет в короткие сроки изучить функциональные возможности программ. Наличие встроенного классификатора условных знаков и возможность его редактирования упрощает процесс векторизации [10]. Рассматривая возможность использования векторизатора «Панорама-редактор» на производстве, следует отметить преимущества и некоторые недостатки данного продукта. На сегодняшний день создание и обновление топографических карт в Республике Казахстан выполняется с использованием двух программ. Масштабы 1:100 000, 1:50 000, 1:25 000 создаются при помощи геоинформационной системы MapInfo Professional, масштабы 1:5 000, 1:2 000, 1:1000 выполняются в программном продукте MicroStation.

Одним из преимуществ программного продукта «Панорама-редактор» является возможность создания и обновления цифровых топографических карт и планов всего масштабного ряда. Это существенно упрощает работу исполнителя. Нет необходимости тратить время на адаптацию при переходе от одной программы к другой. Стоимость программы MicroStation составляет 360300 рублей, профессионального векторизатора «Панорама-редактор» 39900 рублей [11]. Исходя из вышесказанного, можно сделать вывод о целесообразности использования векторизатора «Панорама-редактор» при создании и обновлении карт на производстве в Республике Казахстан.

\section{БИБЛИОГРАФИЧЕСКИЙ СПИСОК}

1. Назарбаев, Н. А. Долгосрочная стратегия развития Республики Казахстан: «Казахстан-2030» [Текст] / Н. А. Назарбаев // Рауан. - Алматы, 1998.

2. Хлебникова, Т. А. Создание цифровых карт и планов средствами ГИС «Панорама» [Текст] : учебно-методическое пособие / Т. А. Хлебникова. - СГГА. - Новосибирск, 2007. $125 \mathrm{c}$. 
3. Степанов, В. В., Демовская Н. В. Основы MicroStation V8 [Текст] : учебное пособие / В. В. Степанов, Н. В. Демовская. - Москва, 2004. - 124 с.

4. Геоинформационная система «Панорама». Создание и редактирование векторных карт [Текст] / КБ Панорама. - Ногинск, 1991-2000. - 22 с.

5. Скоробогатова, А. С., Епифанова М. С., Хлебникова Е. П. Цифровые фотограмметрические системы в топографо-геодезическом производстве Республики Казахстан [Текст] //ИнтерэкспоГео-Сибирь. XIVМеждунар. науч. конгр. : Междунар. науч. конф. «Дистанционные методы зондирования Земли и фотограмметрия, мониторинг окружающей среды, геология»:сб. материалов в 2 т. (Новосибирск, 23-27 апреля 2018 г.). - Новосибирск : СГУГиТ, 2018. - Т. 1. - С. 19-24.

6. Епифанова М. С., Хлебникова Е. П. Исследование возможности создания и обновления цифровых топографических карт и планов на территорию Республики [Текст] // ИнтерэкспоГео-Сибирь. XV Междунар. науч. конгр. : Магистерская научная сессия «Первые шаги в науке» : сб. материалов в 9 т. (Новосибирск, 24-26 апреля 2019 г.). - Новосибирск : СГУГиТ, 2018. - Т. 6. - С. 215-221.

7. Условные знаки для топографических планов масштабов 1:5 000, 1:2 000, 1:1 000, 1:500[Текст]. - Недра. - Москва, 1989. -286 с.

8. ГКИНП (ГНТА)-05-032-09 Руководство по картографическим и картоиздательским работам. [Текст] : геодезические, картографические инструкции, нормы и правила. - Астана, 2009. $-84 \mathrm{c}$.

9. Макаренко, С. А., Ломакин С. В. Картография и ГИС (ГИС "Панорама") [Текст] : учебно-методическое пособие / С.А. Макаренко, С.В. Ломакин. - ФГБОУ ВО Воронежский ГАУ имени императора Петра I. - Воронеж, 2016. - 118 с.

10. Геоинформационная система «Панорама. Руководство пользователя [Электронный pecypc]. - Режим доступа : https:/gisinfo.ru/products/panedit12.htm. - Загл с экр.

11. BentleySystems. MicroStation. Руководство пользователя [Электронный ресурс]. https://store.bentley.com/en/products/applications/11442--MicroStation. - Загл с экр.

(C) М. С. Епифанова, Е. П. Хлебникова, 2021 